\title{
Enzyme-Mediated Production of Sugars from Sago Starch: Statistical Process Optimization
}

\author{
L. LONG WEE, 1 M. S. M. ANNUAR,2 S. IBRAHIM,3
}

AND Y. CHISTI 4

1Faculty of Biotechnology and Life Sciences, Universiti Industri

Selangor, Shah Alam, Malaysia

2Institute of Biological Sciences, University of Malaya,

Kuala Lumpur, Malaysia

${ }_{3}$ Department of Civil Engineering, University of Malaya,

Kuala Lumpur, Malaysia

4School of Engineering, Massey University, Palmerston North, New Zealand

Introduction

Sago palm (Metroxylon sagu) is an agronomically important (Flach and Schuiling, 1989) but relatively underutilized (Karim et al., 2008) indigenous crop of Southeast Asia. About 60 million tons of sago starch are extracted annually from the pith of sago trunks (Wang et al., 1996). Sago palm can potentially yield up to 25 tons of starch per hectare per year, or about three- to four-fold more than crops such as rice, corn, and wheat (Karim et al., 2008). Sago starch is potentially an inexpensive source of fermentable glucose and can be used to produce high-fructose syrup (Abd-Aziz, 2002), a commercial sweetener. Starch from various other sources (e.g., corn, potato, cassava) is commercially used to make glucose via a process that involves the enzymes a-amylase and glucoamylase (Ejiofor et al., 1996). A similar process can be envisaged using sago starch as the substrate. This work reports on the optimal conditions for attaining the combination of maximum conversion rate and yield during enzyme-mediated hydrolysis of sago starch to reducing sugars.

In this study, a fungal glucoamylase was used to hydrolyze sago starch. The objective of the work was to maximize the yield $Y_{p=s}$ of reducing sugars and the reaction velocity $v$ for the production of reducing sugars. Statistical optimization involving a central composite design (CCD) of the response surface method (RSM) was 
used to develop a mathematical model relating $Y_{p=s}$ and $v$ to temperature, $\mathrm{pH}$, agitation speed, substrate concentration, and enzyme loading. The model was used to understand the main effects and the interaction effects among process variables and subsequently to optimize the process.

Response surface methodology (RSM) is a statistical optimization method. RSM is suitable for identifying the effect of individual variables and for efficiently seeking the conditions for an optimum response in a multivariable system (Montgomery, 2001). This method has been successfully applied to optimize fermentation processes (Maddox and Reichert, 1997; Chen, 1981; Grothe et al., 1999; Ratnam et al., 2003; Casas Lo'pez et al., 2004), vegetable oil bioconversion (Cheynier et al., 1983), biomass production (Moresi et al., 1980), and numerous other processes (Panda et al., 1999; Ellaiah et al., 2002; Adinarayaan and Suren, 2005). Effects of temperature, $\mathrm{pH}$, and enzyme dosage on sago starch hydrolysis using bacterial a-amylase, b-glucanase, and pullulanase have been previously studied using statistical design of experiment (Gorinstein et al., 1994). This work presents a simpler hydrolysis process that does not involve any major pretreatment of the substrate. Sago starch and its applications have been reviewed elsewhere (Karim et al., 2008; Abd-Aziz, 2002).

Materials and Methods

\section{Substrate}

Sago starch was obtained from a commercial producer, Wah Chang International (Malaysia). The starch had been isolated from the sago palm Metroxylon sagu.

The starch was dried to a constant weight at 60_C before use. Swinkels (1985) reported the chemical composition of sago starch (dry weight basis, \%) as follows: amylase 27; amylopectin 73; lipids 0.1 ; protein (nitrogen content_6.25) 0.1 ; ash 0.2 ; phosphorus 0.02 .

\section{Enzyme}

Glucoamylase (EC 3.2.1.3) from Aspergillus niger was purchased from Sigma-Aldrich. The specific activity of the enzyme preparation according to the manufacturer was 31.2U_mg_1.

\section{Reaction Conditions}

The starch and enzyme solutions were prepared in 0.05 Macetate buffer at $\mathrm{pH}$ values specified in the RSM design and discussed later. The starch and enzyme solutions were mixed in an automated 2L batch stirred tank reactor (Biostat Bp, Sartorius,

Germany) at a volume ratio of $1: 1$. The initial working volume was $1.5 \mathrm{~L}$. The reactor 
was equipped with two six-bladed Rushton turbine impellers for mixing. The ranges of the five process variables or factors $(\mathrm{pH}$, temperature $\mathrm{T}$, agitation speed $x$, substrate concentration [S], enzyme concentration [E]) were determined by the central composite design of the response surface method, as discussed later. Temperature, $\mathrm{pH}$, and agitation speed were automatically controlled at their specified set points by the process control unit of the reactor. Samples in test tubes were taken every 3 min, a proportionate volume of DNS solution was added and this was immediately followed by quenching of the enzyme activity in a boiling water bath (100_C) for $5 \mathrm{~min}$. The samples were then held at 4_C until analysis. Determination of the reducing sugars was completed within $8 \mathrm{~h}$ of sample collection.

Experimental Design and Statistical Analysis

Experimental design, optimization, and statistical analyses were performed using MINITAB 14 software. A central composite factorial design (CCD) with 66 replicated runs performed randomly in two blocks was used. The design output given by the MINITAB 14 software contained 32 cube points ( 12 center points and 20 axial points) and 2 axial center points.

Linear, quadratic, and interaction effects of the five factors at five levels were statistically evaluated. The five different levels of each variable taken at a central coded value of zero (coded as_2, _1, 0, p1, and p2, respectively) are shown in Table I. The response surface models were fitted to two responses, namely the initial reaction velocity $v$ and the yield of reducing sugars $Y_{p=s}$.

When the factor values are relatively close to optimum, a second-order model is usually required to approximate the response because of curvature in the true response surface (Montgomery, 2005). The behavior of such as system can be characterized by the following full quadratic equation written for three explanatory variables $\mathrm{X}_{1-3}$ :

Full text is available at :

www.tandfonline.com/doi/abs/10.1080/00986445.2011.560513 